\title{
Antioxidant and Hepatoprotective Potential of Dragon Fruit Extract in Opposition to Acetaminophen-Induce Liver Smash Up in Rats
}

\author{
Mihir Y Parmar ${ }^{1,2 *}$, Sachinkumar Sharma ${ }^{2}$, Tribhuvan Singh ${ }^{3}$, Ishimo Steven ${ }^{2}$, Nirali Pandya ${ }^{2}$ and Dinesh Pore ${ }^{1}$ \\ ${ }^{1}$ Bharat Institute of Technology, Jawaharlal Nehru Technological University, India
}

${ }^{2}$ Parul Institute of Pharmacy and Research, Parul University, India

${ }^{3}$ Scient Institute of Pharmacy, Jawaharlal Nehru Technological University, India

Submission: February 14, 2019; Published: March 15, 2019

"Corresponding author: Mihir Y Parmar, Professor Pharmacology, Bharat Institute of Technology, Jawaharlal Nehru Technological University Mangalpally, Hyderabad, Telangana, India

\begin{abstract}
To scrutinize the hepatoprotective and antioxidant potential of methanolic extract of Dragon Fruit (MEDF) against acetaminophen (3g/ $\mathrm{kg}$, p.o. for 3 days) induced liver damage in rats. Rats were pretreated with MEDF (300 and 500mg/kg, p.o) 30 min prior to acetaminophen ingestion for seven days. The extent of defense was measured using levels of serum enzymes like Alanine and Aspartate aminotransferase (ALT \& AST) alkaline phosphatase (ALP), total and direct bilirubin (TBL \& DBL), lactate dehydrogenase (LDH), gamma glutamyl transferees (GGT) and total protein (TP). Additionally, oxidative stress parameters such as levels of Malondialdehyde (MDA), reduced glutathione (GSH) and activity of superoxide dismutase (SOD) and catalase (CAT) along with histological evaluation of liver sections was carried out to shore up the induction of liver damage and hepatoprotective potential. The substantially elevated serum enzyme levels of ALT, AST, ALP, TBL, DBL, GGT LDH and TP, also Oxidative stress parameters MDA, GSH levels and SOD, CAT activities were found to be restored towards normalization by MEDF comparable with silymarin. Pathological changes were in same road supports finding of biochemical evidences of hepatoprotection. MEDF possess an extremely hopeful antioxidant and hepatoprotective potential against acetaminophen induced liver injury.
\end{abstract}

Keywords: Antioxidant; Acetaminophen; Hepatoprotective; Oxidative Stress; Liver

Abbrevations: MEDF: Methanolic Extract of Dragon Fruit; ALT \& AST: Alanine and Aspartate Aminotransferase; ALP: Alkaline Phosphatase; TBL \& DBL: Total and Direct Bilirubin; LDH: Lactate Dehydrogenase; GGT: Gamma Glutamyl Transferees; TP: Total Protein; MDA: Malondialdehyde; GSH: Glutathione; SOD: Superoxide Dismutase; CAT: Catalase

\section{Introduction}

Liver is the vital organ of metabolism and excretion. Because of unique features, liver is also an important target of the toxicity of xenobiotics and oxidative stress [1]. Excessive consumptions of alcohol and viral infections, environmental pollution, hepatic viruses, parasitic infections, and chemotherapeutics are the most common factors known to cause liver damage in developed countries [2]. Drug induced liver damage is a potential complication of nearly every medication that is prescribed. Acetaminophen is a well-known antipyretic and analgesic. Its hepatotoxicity is more common, caused by the reaction metabolite $\mathrm{N}$-acetyl-p- benzoquinoneimine (NAPQI) [3]. Liver diseases are the biggest threat to the world which is characterized with impaired metabolic and secretary functions of liver clinically as jaundice, cirrhosis, hepatitis, liver cancer and ultimately liver failure [4]. About 20,000 deaths found every year due to liver disorders [5]. A common chronic dis ease known as liver fibrosis may lead to end-stage liver cirrhosis and liver cancer [6]. Hepatocellular carcinoma is one of the ten most common tumors in the world with over 2, 50, 000 new cases each year [7].

There are many natural products such as plant and traditional herbal formulation available for the protective effect on liver against damage induced by hepatotoxin. More than 600 commercial herbal products with claimed hepatoprotective role are being sold in all over the world. Around 170 phytoconstituents isolated from 110 plants belonging to 55 families have been reported to show hepatoprotective role. However, only a small proportion of hepatoprotective plants as well as formulations used in traditional medicine are pharmacologically evaluated for their safety and efficacy [8]. 
Genus Hylocereus belongs to the vine cactus from the subfamily of Cactoideae within the family of Cactaceae. It is a native fruit from Mexico, Central and South America and has been cultivated in Vietnam for at least 100 years, following by the French [9]. There are three cultivars of dragon fruit: Hylocereus undatus, red-coloured pericarp with white flesh; Hylocereus polyrhizus, red skinned with red flesh and Selinecereus megalanthus, yellow-coloured with white flesh [10]. Typically, Hylocereus undatus is a cactus plant which possesses fruit as the Red "Dragon Fruit" or Red Pitaya Fruit, the most widely cultivated vine cactus. In addition, it knows as Red Pitaya or Strawberry Pear cactus fruit as well. Commonly, this fruit is named as pitaya because of the bracts or scales on the fruit skin and hence the name of pitaya meaning "the scaly fruit" [11].

In recent years, the fruits of Hylocereus have greatly elevated its popularity worldwide due to its attractive colours, sweet, juicy pleasant taste and have been considered the most beautiful. Besides its red-purple coloration, the fruits of Hylocereus are being highlighted by global cultivators because of its rich source of polyphenolic components and their antioxidant activity [12]. Polyphenolic compounds are an excellent antioxidant and bio-active free radical scavengers, playing an important role in protecting humans [13]. Phenolic is found in abundant in plants, which is the major secondary metabolites of plants, serving in plant defence mechanism for counteracting reactive oxygen species (ROS). In cacti, red-violet betacyanins and yellow betaxanthins are the most important fruit pigments, belonging to betalain pigments [14]. Betalain is a class of water-soluble pigments that provide the colors in a wide ranging of flowers and fruits [15].

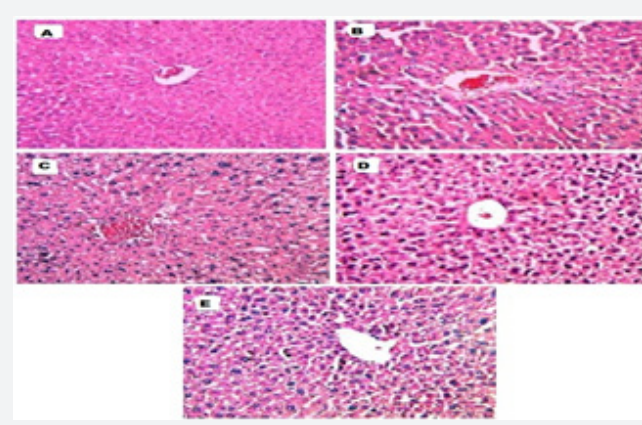

Figure 1: Histological assessment of liver tissue pieces of different groups.

Plant derived natural products such as phenolic compounds (flavonoids), terpenoids, steroids, glycosides, saponins, volatile oils etc. have acknowledged considerable interest in recent years due to their diverse pharmacological properties including antioxidant and hepatoprotective activity [16-20]. Antioxidants play an important role in inhibiting and scavenging radicals, thus providing fortification to humans against various diseases. Silymarin, a standardized extract obtained from seeds of Silybum marianum, is widely used in treatment of liver diseases of varying origins [21]. Seeds of $S$. marianum have been shown to treat liver and gall bladder disorders, including hepatitis, cirrhosis and jaundice and to protect the liver against poisoning from chemicals, environmen- tal toxins, snake bites, insect stings, mushroom poisoning and alcohols [22]. Due to its proven hepatoprotective and antioxidant properties, silymarin is being used in the current study as a standard agent for comparison with of methanolic extract of Dragon fruit [23]. However, no comprehensive evidence has yet been documented for the hepatoprotective activity of Dragon fruit against acetaminophen induced liver damage. Keeping this in mind the present study was planned to assess the hepatoprotective and antioxidant activity of Dragon fruit and its putative mechanisms using acetaminophen induced liver damage in rats.

\section{Materials and Methods}

\section{Fruit material and extraction}

Dragon fruit was collected from local market of Vadodara, Gujarat, India in the month of August 2018. The fruit was identified and authenticated by Department of Sciences, Parul University, Limda, Gujarat, India where a voucher specimen (No. MP-2: 28/8/18) was kept for future reference. Dragon fruit aqueous extract prepared with water. The extract ( $13.5 \%$ yields) was obtained by evaporation using Rotavapour $₫$ (BÜCHI, Switzerland) under reduced pressure. The dry aqueous extract was stored in cool and dry place which further used for the assessment of hepatoprotective potential. All the test and standard suspensions were prepared in the distilled water.

\section{Animals}

Studies were carried out using either sex Wistar albino rats (200-250g). They were obtained from the animal house, Parul Institute of Pharmacy and Research (PIPR), Vadodara, India. The animals were grouped and housed in polyacrylic cages $(38 \times 23 \times$ $10 \mathrm{~cm}$ ) with not more than six animals per cage and maintained under standard laboratory conditions (temperature $22+2^{\circ} \mathrm{C}$ ), relative humidity ( $55 \pm 5 \%$ ) with dark and light cycle $(12 / 12 \mathrm{~h})$.They were allowed free access to standard pellet diet (Amrut feed, Sangli, India) and water ad libitum. The rats were acclimatized to laboratory condition for 15 days before commencement of experiment. Animal studies were approved by the Committee for the Purpose of Control and Supervision of Experiments on Animals (CPCSEA) and conducted according to the regulations of Institutional Animal Ethics Committee (Protocol no. IS 514).

\section{Drugs and chemicals}

Silymarin was obtained as a gift sample from Micro labs, Bangalore, India. AST, ALT, ALP, Bilirubin kits were procured from Span Diagnostics, Surat, India. LDH, GGT kits were procured from Coral Clinical Systems, Goa, India. All other chemicals and reagents used were of analytical grade.

\section{Acute toxicity studies}

Rats were divided into 3 different groups $(n=6)$ and assigned either as vehicle (distilled water, p.o, $5 \mathrm{ml} / \mathrm{kg}$ ), low and high dose of Aqueous extract of Dragon fruit (MEDF) at $3 \mathrm{~g} / \mathrm{kg}$ and $5 \mathrm{~g} / \mathrm{kg}$, p.o respectively. The rats were not fed overnight prior to the treatments. After treatments, the rats were observed for toxicity symp- 
toms and behavioral change for a period of $48 \mathrm{hr}$. The observations continued up to day 14 . Then, the rats were sacrificed after overnight fasting on day 15. Livers were excised for gross necropsy and histopathological examination. There was no lethality in any of the groups. One tenth of the maximum dose of the extract tested for acute toxicity was selected for evaluation of hepatoprotective activity, i.e., $300 \& 500 \mathrm{mg} / \mathrm{kg}$ [24].

\section{Experimental blueprint}

Acetaminophen-induced liver damage in rats [25]: Wistar albino rats were randomly divided into five groups six of each: Group I (Normal control) was received distilled water, p.o, and Group II (Acetaminophen control) was treated with acetaminophen (3g/kg/d, p.o.), for 3 days. Group III (Test- 1 ) and Group IV (Test-2) were pretreated with MEDF at a dose of $300,500 \mathrm{mg} / \mathrm{kg}$ and Group V (Standard) Silymarin at a dose $200 \mathrm{mg} / \mathrm{kg} / \mathrm{d}$, p.o., respectively $30 \mathrm{~min}$ prior to acetaminophen ingestion for 3 days.

\section{Effects of MEDF on serum enzymes}

At the end of last treatment, blood was collected from retro-orbital plexus from all groups of rats after $24 \mathrm{~h}$ overnight fasting, on 4th day between $10.00 \mathrm{AM}$ and $11.00 \mathrm{AM}$. All blood samples were allowed to clot for $45 \mathrm{~min}$ at room temperature. Serum was separated by centrifugation at $2500 \mathrm{rpm}$ at $4^{\circ} \mathrm{C}$ for $15 \mathrm{~min}$ and used for the estimation of various serum enzymes like Alanine and Aspartate aminotransferase (ALT \& AST), alkaline phosphatase (ALP), total and direct bilirubin (TBL \& DBL), lactate dehydrogenase (LDH), gamma glutamyl transferase (GGT) and total protein (TP) [26].

After collection of blood samples, the rats were sacrificed by light ether anesthesia and their livers were excised, rinsed in ice cold normal saline, followed by $0.15 \mathrm{M}$ Tris- $\mathrm{HCl}$ ( $\mathrm{pH}$ 7.4) blotted dry and weighed. A small $10 \%(\mathrm{w} / \mathrm{v})$ portion of the Liver was homogenized in chilled Phosphate buffered saline (50 mM, pH 7.4) using a Potter Elvehjehm Teflon homogenizer. The homogenate obtained was centrifuged in a cooling centrifuge at $1,000 \times$ g for 10 min at $4^{\circ} \mathrm{C}$ to remove nuclei and unbroken cells. The pellet was discarded, and portion of supernatant was again centrifuged at Table 1a: Level of serum enzyme in different groups.

\begin{tabular}{|c|c|c|c|c|c|}
\hline \multirow{2}{*}{ Group } & AST & ALT & ALP & TBL & DBL \\
\cline { 2 - 6 } & (IU/L) & (IU/L) & (KAU/dl) & (mg/dl) & (mg/dl) \\
\hline I-Normal control & $47.2 \pm 1.5$ & $29.6 \pm 1.1$ & $9.7 \pm 0.25$ & $0.8 \pm 0.04$ & $0.6 \pm 0.1$ \\
\hline II-Acetaminophen control & $180.4 \pm 3.4 \mathrm{a}^{* * *}$ & $125.0 \pm 2.6 \mathrm{a}^{* * *}$ & $59.9 \pm 0.5 \mathrm{a}^{* *}$ & $12.5 \pm 1.2 \mathrm{a}^{*}$ & $6.9 \pm 0.81 \mathrm{a}^{* *}$ \\
\hline III-Test-1 & $133.17 \pm 1.62 \mathrm{~b}^{*}$ & $85.8 \pm 1.10 \mathrm{~b}^{*}$ & $46.13 \pm 0.65 \mathrm{~b}^{*}$ & $4.9 \pm 0.09 \mathrm{~b}^{*}$ & $2.8 \pm 0.04 \mathrm{~b}^{*}$ \\
\hline IV-Test-2 & $102.33 \pm 1.48 \mathrm{~b}^{*}$ & $69.75 \pm 1.68 \mathrm{~b}^{*}$ & $41.08 \pm 0.8 \mathrm{~b}^{*}$ & $2.64 \pm 0.06 \mathrm{~b}^{*}$ & $2.05 \pm 0.37 \mathrm{~b}^{*}$ \\
\hline V-Standard & $58.6 \pm 0.5 \mathrm{~b}^{* *}$ & $49.0 \pm 0.4 \mathrm{~b}^{* *}$ & $14.0 \pm 0.09 \mathrm{~b}^{* *}$ & $1.7 \pm 0.25 \mathrm{~b}^{* *}$ & $1.7 \pm 0.14 \mathrm{~b}^{* *}$ \\
\hline
\end{tabular}

Table $1 \mathrm{~b}$ :Level of serum enzyme in different groups.

\begin{tabular}{|c|c|c|c|}
\hline Group & LDH (U/L) & GGT (U/L) & TP (mg/ml) \\
\hline I-Normal control & $345.2 \pm 8.3$ & $17.9 \pm 0.7$ & $10.8 \pm 0.03$ \\
\hline II-Acetaminophen control & $1791.2 \pm 10.8 \mathrm{a}^{* * *}$ & $79.8 \pm 2.1 \mathrm{a}^{* *}$ & $4.2 \pm 0.02 \mathrm{a}^{* *}$ \\
\hline III-Test-1 & $1083.26 \pm 7.19 \mathrm{~b}^{*}$ & $63.14 \pm 0.81 \mathrm{~b}^{*}$ & $9.52 \pm 0.03 \mathrm{~b}^{*}$ \\
\hline
\end{tabular}

$12,000 \times \mathrm{g}$ for $20 \mathrm{~min}$ at $4^{\circ} \mathrm{C}$ obtain a post- mitochondrial supernatant which was used for enzyme analysis [27-28]. The contents of malondialdehyde (MDA), reduced glutathione (GSH), Superoxide dismutase (SOD) and Catalase (CAT) activity [29] were estimated spectrophotometrically using above post-mitochondrial supernatant.

\section{Histological studies}

A Small piece of liver were fixed in 10\% neutral buffered formalin and subsequently embedded in paraffin. A transverse section of $5 \mu \mathrm{m}$ was cut from each sample and stained with haematoxylin and eosin. Histopathological assessment (light microscopy) was performed on randomized sections of liver [30].

\section{Statistical analysis}

The experimental outcomes were expressed as Mean \pm SEM for six animals in all groups. All parameters were analyzed statistically using one-way analysis of variance (ANOVA), followed by Duntt's multiple comparison test (DMCT) using Graph Pad prism $\mathrm{P}<0.05$.

\section{Results}

\section{Acute toxicity study}

There was no morbidity and mortality observed throughout the study. Dragon fruit was found not toxic to the experimental rats up to the high dose of $5 \mathrm{~g} / \mathrm{kg}$.

\section{Effects of MEDF on serum enzyme levels in different groups}

Significantly elevated levels of AST, ALT, ALP, TBL, DBL, LDH and GGT whereas decreased level of TP were observed in acetaminophen control ( $3 \mathrm{~g} / \mathrm{kg}$, p.o. for 3 days) compared to normal control. Treatments with MEDF (Test-1 \& Test-2) received 300 and $500 \mathrm{mg} / \mathrm{kg}$, p.o. as well as standard (silymarin) received 200 $\mathrm{mg} / \mathrm{kg}$, p.o. for 3 days caused significant decline in above serum biomarkers and significantly enhanced the level of TP (Table 1a \&1b). 


\section{Advanced Research in Gastroenterology \& Hepatology}

\begin{tabular}{|c|c|c|c|}
\hline IV-Test-2 & $949.34 \pm 11.60 \mathrm{~b}^{*}$ & $54.90 \pm 1.04 \mathrm{~b}^{*}$ & $8.71 \pm 0.04 \mathrm{~b}^{*}$ \\
\hline V-Standard & $521.2 \pm 3.5 \mathrm{~b}^{* *}$ & $39.4 \pm 1.2 \mathrm{~b}^{* *}$ & $9.2 \pm 0.04 \mathrm{~b}^{* *}$ \\
\hline
\end{tabular}

Effects of MEDF on Oxidative stress parameters in different groups

Oxidative stress parameters of post mitochondrial supernatant were measured. A significant $(\mathrm{P}<0.01)$ increase in MDA while declines in GSH levels, SOD and CAT activities were found in ac-

Table 2: Level of oxidative stress parameters in different groups.

\begin{tabular}{|c|c|c|c|c|c|}
\hline \multirow{2}{*}{ Group } & GSH & MDA & SOD & CAT & DBL \\
\cline { 2 - 6 } & (nM/mg protein) & (nM/mg protein) & (U/mg protein) & (U/mg protein) & (mg/dl) \\
\hline I-Normal control & $12.14 \pm 0.16$ & $2.8 \pm 0.02$ & $1.71 \pm 0.02$ & $28.17 \pm 1.25$ & $0.6 \pm 0.1$ \\
\hline II-Acetaminophen control & $7.10 \pm 0.12 \mathrm{a}^{* *}$ & $15.8 \pm 0.01 \mathrm{a}^{* *}$ & $0.46 \pm 0.03 \mathrm{a}^{* *}$ & $9.78 \pm 0.87 \mathrm{a}^{* *}$ & $6.9 \pm 0.81 \mathrm{a}^{* *}$ \\
\hline III-Test-1 & $7.80 \pm 0.06 \mathrm{~b}^{*}$ & $5.6 \pm 0.06 \mathrm{~b}^{*}$ & $1.47 \pm 0.12 \mathrm{~b}^{*}$ & $11.29 \pm 0.3 \mathrm{~b}^{*}$ & $2.8 \pm 0.04 \mathrm{~b}^{*}$ \\
\hline IV-Test-2 & $10.54 \pm 0.11 \mathrm{~b}^{*}$ & $5.1 \pm 0.01 \mathrm{~b}^{*}$ & $1.53 \pm 0.03 \mathrm{~b}^{*}$ & $14.98 \pm 0.9 \mathrm{~b}^{*}$ & $2.05 \pm 0.37 \mathrm{~b}^{*}$ \\
\hline V-Standard & $11.47 \pm 0.41 \mathrm{~b}^{* *}$ & $4.7 \pm 0.03 \mathrm{~b}^{*}$ & $1.59 \pm 0.12 \mathrm{~b}^{* *}$ & $19.82 \pm 1.5 \mathrm{~b}^{* *}$ & $1.7 \pm 0.14 \mathrm{~b}^{* *}$ \\
\hline
\end{tabular}

\section{Liver histology}

Pathological examination of normal control animals revealed normal cellular architecture with distinct hepatic cells, sinusoidal spaces and central vein (1A). In acetaminophen control, there was a severe disarrangement and degeneration of normal hepatic cells with centrilobular necrosis extending to mid zone and sinusoidal hemorrhages and dilation (1B). Treatments with MEDF (Test-1 \& Test-2) (1C \& 1D) and silymarin (1E) showed evidence of preservation of normal structure $\&$ architecture of hepatocytes (b).

\section{Debate}

Protection against acetaminophen-induced liver damage has been taken as a test for potential hepatoprotective agent by several investigators. Acetaminophen is a common antipyretic agent which is safe in therapeutic doses but can produce fatal hepatic necrosis in man, rats and mice with toxic doses. Hepatotoxicity of acetaminophen has been attributed to the formation of highly reactive toxic metabolite $\mathrm{N}$-acetyl-p-benzoquinoneimine (NAPQI) [31].

The rise in serum levels of AST and ALT has been attributed to the damaged structural integrity of the liver [29], because these are cytoplasmic in location and are released into circulation after cellular damage [32]. Assessment of liver function can be made by estimating the activities of serum AST, ALT and ALP, which are enzymes originally present in higher concentration in cytoplasm [26], when there is hepatopathy, these enzymes leak into blood stream in conformity with the extent of liver damage. ALT is frequently included in biochemical profiles for the purpose of assessing hepatic injury [33]. The elevation of ALP indicates the disturbed excretory function of liver.

GGT and ALP are membrane bound enzymes, which are released unequally depending on the pathological phenomenon. The elevation of serum GGT concentrations is regarded as one of the most sensitive indices of hepatic damage [34]. LDH is catalyses the conversion of lactate to pyruvate using NAD+ as coenzyme of etaminophen control as compared to normal control. Treatments with MEDF (Test-1 \& Test-2) and standard (silymarin) exhibited significant decrease in MDA levels while significant elevation in GSH level, SOD and CAT activity as compared to acetaminophen control (Table 2).
NAD [26]. The increase in LDH activity in serum may be due to leakage of the enzyme from the tissues into the blood on account of cellular injury. An elevation in the levels of the serum marker enzymes in generally regarded as one of the most sensitive index of the hepatic damage [29].

In the present study administration of acetaminophen treated rats showed an increase in the levels of AST, ALT, ALP, GGT and LDH when compared with control rats. Oral administration of MEDF (Test-1 \& Test-2) and silymarin to acetaminophen treated rats showed an inhibition in the elevated levels of serum AST ALT, ALP, LDH and GGT levels than acetaminophen alone treated rats. Bilirubin is well known metabolic breakdown product of blood heme with great biological and diagnostic values. Bilirubin is one of the most clinical clues to the severity of necrosis and its accumulation is a measure of binding, conjugation and excretory capacity of hepatocyte. In the present study acetaminophen hepatotoxic rats showed a significant increase in the level of serum TBL and DBL when compared with control rats. Oral administration of MEDF (Test-1 \& Test-2) and silymarin to acetaminophen treated rats showed an inhibition in the elevated levels of serum TBL and DBL than acetaminophen alone treated rats. This decrease in serum bilirubin after treatment with these extracts in liver damage induced by acetaminophen, indicated the effectiveness of these extracts in normal functional status of the liver.

Proteins are important organic constituents of the animal cells playing a vital role in the process of interactions between intra and extra cellular media. Being a part of cell membrane and as an enzyme, protein participates the intricately balanced sub cellular fractions. The depletion in the protein levels might be because of their metabolism to liberate energy during paracetamol toxicity. Protein plays a major role in the synthesis of microsomal detoxifying enzymes and helps to detoxify the toxicants, which enter into the animal body [35]. In the present study administration of acetaminophen treated rats showed decrease in the level of TP when compared with control rats. Oral administration of MEDF (Test-1 
\& Test-2) and silymarin to acetaminophen treated rats showed an increase the level of serum TP than acetaminophen alone treated rats.

NAPQI is initially detoxified by conjugation with GSH to form mercapturic acid [36]. However, when the rate of NAPQI formation exceeds the rate of detoxification by GSH, it oxidizes tissue macromolecules such as lipid or -SH group of proteins and alters the homeostasis of calcium after depleting GSH. The non-enzymic antioxidant, GSH is one of the most abundant tripeptides present in the liver. Its functions are mainly concerned with the removal of free radical (FR) species such as hydrogen peroxide $\left(\mathrm{H}_{2} \mathrm{O}_{2}\right)$, super oxide radicals (0-2) and maintenance of membrane protein thiols and as a substrate for glutathione peroxidase (GPx) and glutathione-s- transferase (GST) [37]. In the present study, the decreased level of GSH has been associated with elevations in the levels of end products (MDA) of LPO in acetaminophen control.

The increase in MDA level in liver suggests enhanced LPO leading to tissue damage and failure of antioxidant defense mechanisms to prevent formation of excessive FR. Treatment with MEDF (Test-1 \& Test-2) and silymarin significantly reverse the above changes. SOD has been reported as one of the most important enzymes in the enzymatic antioxidant defense system [38]. Catalase is an enzymatic antioxidant widely distributed in all animal tissue and the highest activity is found in the red cells and in liver [39]. SOD offers protection form highly reactive $\mathrm{O}_{2}$ and converts them to form $\mathrm{H}_{2} \mathrm{O}_{2}$ and $\mathrm{O}_{2}$. Because $\mathrm{H}_{2} \mathrm{O}_{2}$ is still harmful to cells, CAT and GPx further catalyse the decomposition of $\mathrm{H}_{2} \mathrm{O}_{2}$ to $\mathrm{H}_{2} \mathrm{O}$ [40]. Thus, the coordinate actions of various cellular antioxidants in mammalian cells are critical for effectively detoxifying free radicals.

Decrease in activity of SOD and CAT is a sensitive enzymatic index in liver damage, might reduce protection against free radicals. In the present study, it was observed that treatment with MEDF (Test-1 \& Test-2) and silymarin caused a significant elevated in the hepatic SOD and CAT activity which were decreased in acetaminophen control. This show MEDF prevents the accumulation of excessive FR that might lessen oxidative damage to the tissues and improve the activities of the hepatic antioxidant enzyme. The hepatoprotective effect MEDF (Test-1 \& Test-2) was further substantiated by histopathological assessment in comparison with acetaminophen control.

The rise in serum levels of AST and ALT has been attributed to the damaged structural integrity of the liver [29], because these are cytoplasmic in location and are released into circulation after cellular damage [26]. Assessment of liver function can be made by estimating the activities of serum AST, ALT and ALP, which are enzymes originally present in higher concentration in cytoplasm [41], when there is hepatopathy, these enzymes leak into blood stream in conformity with the extent of liver damage. ALT is frequently included in biochemical profiles for the purpose of assessing hepatic injury. The elevation of ALP indicates the disturbed excretory function of liver. GGT and ALP are membrane bound enzymes, which are released unequally depending on the patho- logical phenomenon. The elevation of serum GGT concentrations is regarded as one of the most sensitive indices of hepatic damage. $\mathrm{LDH}$ is catalyses the conversion of lactate to pyruvate using NAD+ as coenzyme of NAD [42].

The increase in LDH activity in serum may be due to leakage of the enzyme from the tissues into the blood on account of cellular injury. An elevation in the levels of the serum marker enzymes in generally regarded as one of the most sensitive index of the hepatic damage [43]. In the present study administration of acetaminophen treated rats showed an increase in the levels of AST, ALT, ALP, GGT and LDH when compared with control rats. Oral administration of MEDF (Test-1 \& Test-2) and silymarin to acetaminophen treated rats showed an inhibition in the elevated levels of serum AST, ALT, ALP, LDH and GGT levels than acetaminophen alone treated rats.

Bilirubin is well known metabolic breakdown product of blood heme with great biological and diagnostic values. Bilirubin is one of the most clinical clues to the severity of necrosis and its accumulation is a measure of binding, conjugation and excretory capacity of hepatocyte. In the present study acetaminophen hepatotoxic rats showed a significant increase in the level of serum TBL and DBL when compared with control rats. Oral administration of MEDF (Test-1 \& Test-2) and silymarin to acetaminophen treated rats showed an inhibition in the elevated levels of serum TBL and DBL than acetaminophen alone treated rats.

This decrease in serum bilirubin after treatment with these extracts in liver damage induced by acetaminophen indicated the effectiveness of these extracts in normal functional status of the liver. Proteins are important organic constituents of the animal cells playing a vital role in the process of interactions between intra and extra cellular media. Being a part of cell membrane and as an enzyme, protein participates the intricately balanced sub cellular fractions. The depletion in the protein levels might be because of their metabolism to liberate energy during paracetamol toxicity. Protein plays a major role in the synthesis of microsomal detoxifying enzymes and helps to detoxify the toxicants, which enter into the animal body [44].

In the present study administration of acetaminophen treated rats showed decrease in the level of TP when compared with control rats. Oral administration of MEDF (Test-1 \& Test-2) and silymarin to acetaminophen treated rats showed an increase the level of serum TP than acetaminophen alone treated rats. NAPQI is initially detoxified by conjugation with GSH to form mercapturic acid [36]. However, when the rate of NAPQI formation exceeds the rate of detoxification by GSH, it oxidizes tissue macromolecules such as lipid or -SH group of proteins and alters the homeostasis of calcium after depleting GSH. The non-enzymic antioxidant, GSH is one of the most abundant tripeptides present in the liver. Its functions are mainly concerned with the removal of free radical (FR) species such as hydrogen peroxide (H2O2), super oxide radicals $(0-2)$ and maintenance of membrane protein thiols and as a substrate for glutathione peroxidase (GPx) and glutathione-s- 
transferase (GST) [45].

In the present study, the decreased level of GSH has been associated with elevations in the levels of end products (MDA) of LPO in acetaminophen control. The increase in MDA level in liver suggests enhanced LPO leading to tissue damage and failure of antioxidant defense mechanisms to prevent formation of excessive FR. Treatment with MEDF (Test-1 \& Test-2) and silymarin significantly reverse the above changes. SOD has been reported as one of the most important enzymes in the enzymatic antioxidant defense system [26]. Catalase is an enzymatic antioxidant widely distributed in all animal tissue and the highest activity is found in the red cells and in liver [30]. SOD offers protection form highly reactive $\mathrm{O}$-2and converts them to form $\mathrm{H}_{2} \mathrm{O}_{2}$ and $\mathrm{O}_{2}$. Because $\mathrm{H}_{2} \mathrm{O}_{2}$ is still harmful to cells, CAT and GPx further catalyse the decomposition of $\mathrm{H}_{2} \mathrm{O}_{2}$ to $\mathrm{H} 2 \mathrm{O}$ [29].

Thus, the coordinate actions of various cellular antioxidants in mammalian cells are critical for effectively detoxifying free radicals. Decrease in activity of SOD and CAT is a sensitive enzymatic index in liver damage, might reduce protection against free radicals. In the present study, it was observed that treatment with MEDF (Test-1 \& Test-2) and silymarin caused a significant elevated in the hepatic SOD and CAT activity which were decreased in acetaminophen control. This show MEDF prevents the accumulation of excessive FR that might lessen oxidative damage to the tissues and improve the activities of the hepatic antioxidant enzyme. The hepatoprotective effect MEDF (Test-1 \& Test-2) was further substantiated by histopathological assessment in comparison with acetaminophen control.

\section{Authors Contributions}

MP, IS and NP has performed experimental designed, literature search and animal treatment. MP and IS have carried out biochemical and statistical analysis as well as interpretation of the data. MP and SS participated in histopathological investigation. MP and TS involve in writing of the manuscript. MP and SS have review and edited manuscript.

\section{References}

1. Huo HZ, Wang B, Liang YK, Bao YY, Gu Y (2011) Hepatoprotective and Antioxidant Effects of Licorice Extract against $\mathrm{CC}_{14}$ - Induced Oxidative Damage in Rats. Int J Mol Sci 12(10): 6529-6543.

2. Alshawsh MA, Abdulla MA, Ismail S, Amin ZA (2011) Hepatoprotective effects of Orthosiphon stamineus extract on thioacetamide-induced liver cirrhosis in rats. Evid Based Compl Alt Med 1-6.

3. Shah VV, Deval K (2011) Hepatoprotective activity of leaves of Parkinsonia aculeata linn against paracetamol induced hepatotoxicity in rats. Int J Pharmacol 1(2): 59-66.

4. Goyal R, Ravishankar B, Shukla VJ, Singh M (2012) Hepatoprotective Activity of Rohitaka ghrita against Paracetamol Induced Liver Injury in Rat. Pharmacologia 3(7): 227-232.

5. Sharma B, Sharma UK (2010) Hepatoprotective activity of some indigenous plants. Int J Pharm Tech Res 2(1): 568-572.

6. Ao ZH, Xu ZH, Lu ZM, Xu HY, Zhang XM, Dou WF (2009) Niuchangchih (Antrodia camphorata) and its potential in treating liver diseases. J Ethnopharmacol 121(2): 194-212.
7. Meganathan M, Madhana MG, Sasikala P, Mohan J, Gowdhaman N, et al. (2011) Evaluation of antioxidant effect of Omega 3-fatty acid against paracetamol induced liver injury in albino rats. Global J Pharmacol 5(1): 50-53.

8. Nabavi SM, Hajizadeh Moghaddam A, Fazli M, Bigdellou R, Mohammadzadeh S, et al. (2012) Hepatoprotective activity of Allium paradoxum. Europ Rev Med Pharmacol Sci 16(3): 43-46.

9. Mizrahi Y, Nerd A, Nobel PS (1997) Cacti as crops. Hort Rev 18: 291319.

10. Le Bellec F, Vaillant F, Imbert E (2006) Pitahaya (Hylocereus spp.): a new fruit crop, a market with a future. Fruits 61(4): 237-250.

11. Wybraniec S, Mizrahi Y (2002) Fruit Flesh Betacyanin Pigments in $\mathrm{Hy}$ locereus Cacti. J Agric Food Chem 50(21): 6086-6089.

12. Hor SY, Ahmad M, Farsi E, Yam MF, Hashim MA, et al. (2012) Safety assessment of methanol extract of red dragon fruit (Hylocereus polyrhizus): acute and subchronic toxicity studies. Regulatory Toxicol and Pharmacol 63(1): 106-114.

13. Barros A, Gironés Vilaplana A, Texeira A, Baenas N, Domínguez Perles $\mathrm{R}$ (2015) Grape stems as a source of bioactive compounds: application towards added-value commodities and significance for human health. Phytochem Rev 14(6): 921-931.

14. Stintzing FC, Schieber A, Carle R (2002) Betacyanins in fruits from red-purple pitaya, Hylocereus polyrhizus (Weber) Britton \&amp; Rose. Food Chem 77(1): 101-106.

15. Strack D, Vogt T, Schliemann W (2003) Recent advances in betalain research. Phytochem 62(3): 247-269.

16. Defeudis FV, Papadopoulos V, Drieu K (2003) Ginkgo biloba extracts and cancer: a research area in its infancy. Fundam Clin Pharmacol 17(4): 405-417.

17. Takeoka GR, Dao LT (2003) Antioxidant constituent of almond [Prunus dulcis (Mill.) Webb DA] Hulls. J Agric Food Chem 51(2): 496-501.

18. Quyang MA, He ZD, Wu CL (2003) Antioxidative activity of glycosides from Ligustrum sinense. Nat Prod Res 17(6): 381-387.

19. Banskota AH, Tezuka Y, Adnyana IK, Xiong Q Hase K (2000) Hepatoprotective effect of Commbretum quadrangulare and its constituents. Biol Pharm Bull 23(4): 456-460.

20. Yohikawa M, Morikawa T, Kashima Y, Ninomiya K, Matsuda H (2003) Structure of New dammarane type triterpene saponins from the flower buds of Panax notoginseng and hepatoprotective effects of principal ginseng saponins. J Nat Prod 66(7): 922-927.

21. Janbaz KH, Gilani AH (2000) Studies on preventive and curative effects of berberine on chemical induced hepatotoxicity in rodents. Fitoter 71(1): 25-33.

22. Gilani AH, Janbazz KH (1995) Preventive and curative effects of Artemisia absinthium on paracetamol and $\mathrm{CCl}_{4}$-induced hepatotoxicity. Gen Pharmacol 26(2): 309-315.

23. Parmar Mihir Y, Tejal R Gandhi (2008) Hepatoprotective herbal drug, silymarin from experimental pharmacology to clinical medicine. Pharmacognosy Reviews 2(3): 102-109.

24. Mihir Y Parmar (2011) Mitochondrial protection: Mechanism of Amomum subulatum Roxb. seeds extract against liver damage in mice. Indian J Pharmacology 43(6): 671-675.

25. Mihir Y Parmar (2013) Hepatoprotective and antioxidant activity of methanolic extract of Vetiveria Zizanioides roots against paracetamol-induced liver damage in rats. Life Science Journal 10(4): 11841190.

26. Mihir Y Parmar (2008) Hepatoprotective activity of Vetiveria zizanioides linn. against ethanol-induced liver damage in rats. Pharmacognosy 
magazine 4(16): 1-8.

27. Mihir Y Parmar, PA Shah, SS Al-Rejaie, KA Al-Hosaini, TR Gandhi (2013) Amomum subulatum roxb seeds extract ameliorates paracetamol-induced hepatotoxicity in rats. Experimental biology 27(1).

28. Singh KS, Kumar VR, Rajat S (2010) N-acetylcysteine inhibits hyperglycemia-induced oxidative stress and apoptosis markers in diabetic neuropathy. J Neurochem 112(1): 77-91.

29. Shah Purvi, Parmar Mihir, Thakkar Vaishali, Tejal Gandhi (2009) Hepatoprotective activity of Hordeum Vulgare linn. Seeds Against Paracetamol-induced liver damage in rats. Journal of Young Pharmacists 1 : 336-340.

30. Shah Purvi, Parmar Mihir, Thakkar Vaishali, Tejal Gandhi (2009) Hepatoprotective activity of Hordeum Vulgare linn. Seeds Against ethanol-induced liver damage in rats. Pharmacology online 2: 538-545.

31. Savides MC, Oehme FW (1982) Acetaminophen and its toxicity. J Appl Toxicol 3(2): 95-111.

32. Sallie R, Tredger JM, William R (1991) Drug and liver. Biopharmaceutical Drug Disposition 12: 251-259.

33. Willianson EM, Okpako DT, Evans FJ (1996) Selection, Preparation and Pharmacological Evaluation of Plant Material. England (Chichester): John Wiley and Sons Ltd 1: 131-154.

34. Szczeklik E, Orlowski M, Szewes A (1961) Serum gamma glutamyl peptidase activity in liver disease. Gastroenterol 41: 353-359.

35. Ramasamy R (1987) Effects of sevin on blood free amino acids level of the fish sarotherodon mossambicus. Environ Ecol 5: 633-637.

36. Moore M, Thor H, Moore G, Nelson S, Moldeus P, et al. (1985) The toxicity of acetaminophen and $\mathrm{N}$-acetyl P-benzoquinoneimine in isolated hepatocytes is associated with thio depletion and increased cystosolic $\mathrm{Ca}^{2+}$. J Biol Chem 260(24): 13035-13040.

37. Gupta SK, Kochupillai V, Singh N, Gupta YK, Joshi S (2001) Chemopreventive activity of Withania somnifera in experimentally induced fibrosarcoma tumors in Swiss albino mice. Phytother Res 15(3): 240-244.

38. Curtis SJ, Moritz M, Snodgrass PJ (1972) Serum enzymes derived from liver cell fraction and the response to carbon tetrachloride intoxication in rats. Gastroenterol 62(1): 84-92.

39. Chance B, Green DS, Stein, Roughton RJW (1952) The mechanism of catalase action steady state analysis. Arch Biochem Biophy 37(2): 301321.

40. Hayes JD, Flanagan JU, Jowsey IR (2005) Glutathione transferases. Annl Rev Pharmacol Toxicol 45: 51-88.

41. Mihir Y Parmar (2013) Hepatoprotective potential of Methanolic Extract of Vetiveria Zizanioides Roots against Carbon Tetrachloride-Induced Acute Liver Damage in Rats. Digest Journal of Nanomaterials \& Biostructures 8(2): 835-844.

42. Burtis LA, Ashwood ER (1986) Textbook for Clinical Chemistry. WB Saunders Company, Philadelphia, Pennsylvania, USA.

43. Kapil A, Suri OP, Koul IB (1995) Antihepatotoxic effects of chorogenic acid from Anthrocephalus cadamba. Phytother Res 9: 189-193.

44. Ramasamy R (1987) Effects of sevin on blood free amino acids level of the fish sarotherodon mossambicus. Environ Ecol 5: 633-637.

45. Gupta SK, Kochupillai V, Singh N, Gupta YK, Joshi S (2001) Chemopreventive activity of Withania somnifera in experimentally induced fibrosarcoma tumors in Swiss albino mice. Phytother Res 15(3): 240-244.

This work is licensed under Creative

Commons Attribution 4.0 License

DOI: 10.19080/ARGH.2019.12.555846 